www.nature.com/pj

\title{
EDITORIAL
}

\section{A new era of Polymer Journal: a message from the SPSJ President}

Polymer Journal (2010) 42, 1; doi:10.1038/pj.2009.305

$\mathrm{T}$

he Society of Polymer Science, Japan (SPSJ) launched Polymer Journal in 1970, primarily to provide members and their colleagues with the opportunity to disseminate their research results across the world. At that time, Japanese polymer science was just beginning to flourish. Forty years later, it is now almost impossible to find an issue of any chemistry or polymer science journal without a contribution from an SPSJ member, and Polymer Journal is a leading journal in the field of polymer science.

The world has changed dramatically in the past four decades, and so has scientific publishing. When Polymer Journal was founded, few researchers were aware of, or interested in, such statistical jargon as impact factor, citation number, citation half-lifetime or $h$-index. Although often used too excessively, these terms are now common currency in the evaluation of journals and researchers. Electronic submission, peer review and publishing are essentially mandatory for high-quality journals, as authors increasingly demand fast and efficient publication.

In response to these developments, Polymer Journal has made an important change for 2010. From this January issue, the journal will be published in partnership with Nature Publishing Group (NPG), while SPSJ retains the copyright of journal contents and control of editorial processes and Editorial Board member selection. In particular, the Society is pleased that Polymer Journal represents the first title in this field to join the group's growing portfolio of leading titles. With NPG's state-of-the-art publishing practices, worldwide sales network and experienced staff, SPSJ and the journal's Editorial Board are unequivocally convinced that Polymer Journal will firmly establish its presence as a leading international publication providing an exciting forum for polymer science and related interdisciplinary fields, which now extend to chemistry, physics, biology and materials science.

Most importantly, Polymer Journal's evolution will not be successful without original, innovative and appealing articles from international

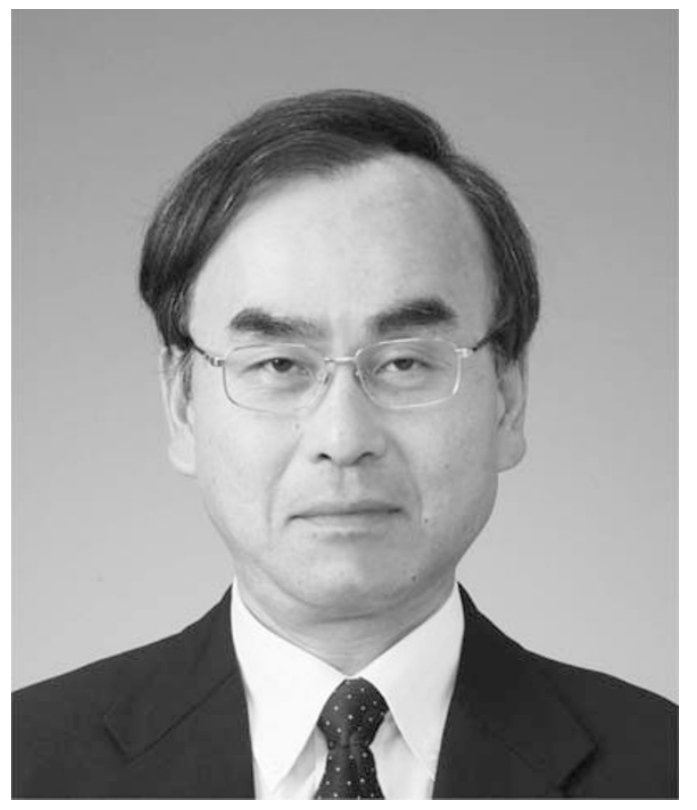

colleagues. SPSJ and the Editorial Board welcome your contributions and invite you to submit your best work to the journal.

On behalf of SPSJ, I would like to express my sincere appreciation for the efforts of the Editorial Board members and Editors-in-Chief, both past and present, particularly Professors Mitsuru Ueda and Toshikazu Takata.

Welcome to the new era of Polymer Journal!

Mitsuo Sawamoto President Society of Polymer Science, Japan 